\title{
Movimentos sociais e cidade: uma análise das formas de ação coletiva recentes em Belo Horizonte
}

Social movements and the city: an analysis of the recent forms of collective action in Belo Horizonte

\author{
Flavia de Paula Duque Brasil* \\ Ricardo Carneiro** \\ Thaysa Sonale Almeida Silva*** \\ Rodolfo Pinhón Bechtlufft ${ }^{* * * *}$
}

\section{Resumo:}

O ambiente contemporâneo marca-se pelo alargamento das formas de participação social, pela pluralização dos movimentos sociais e formas de ação coletiva. Em Belo Horizonte, além das manifestações associadas às questões nacionais desde 2013, ampliam-se os movimentos sociais que retematizam a cidade questionando a sua mercantilização, defendendo o direito à cidade, uma apropriação mais inclusiva do espaço urbano, aspectos relativos à inclusão social e a democratização da gestão municipal. O trabalho - de natureza exploratória e qualitativa - aborda os movimentos sociais na cidade na última década, com pautas relacionadas à cidade e ao direito à cidade, tendo por objetivo analisar as formas de ação coletiva, mediante repertórios diversos, incluindo a interação com o governo local. A partir da revisão de desenvolvimentos teóricos relativos à temática, busca-se mapear os referidos movimentos e compreender como se constituíram em atores coletivos, quais os significados compartilhados e especialmente, quais as agendas e repertórios de ação e interação com o governo local e quais os desdobramentos de sua atuação.

Palavras-chave: Movimentos sociais. Ação coletiva. Participação social. Direito à cidade. Belo Horizonte.

\begin{abstract}
The contemporary environment has an inherent diversity of social participation forms, pluralization of the movements and forms of collective action. In Belo Horizonte, in addition to the manifestations associated with national issues since 2013, it is possible to notice an increase of social movements that are redefining the city of Belo Horizonte by questioning its mercantilization, claiming for the right to the city, a more inclusive appropriation of the urban space and aspects related to social inclusion and democratization of the municipal management. This exploratory and qualitative work addresses the social movements in the city of Belo Horizonte in the last decade, with guidelines referred to the city and the right to the city, aiming to analyze how forms of collective action, through several repertories, including interaction with the local government. By the review of theoretical developments related to social movements, it is sought to understand who the actors are and how they were constituted in collective actors, what are the shared meanings and especially, what agendas and repertoires of actions and interaction with local government and what are the consequences of their acting.
\end{abstract}

Keywords: Social movements. Collective action. Social participation. Right to the city. Belo Horizonte.

\footnotetext{
* Especialista em Urbanismo pela UFMG. Mestre em Sociologia e Doutora em Sociologia pela UFMG. Professora da Escola de Governo da Fundação João Pinheiro.

** Doutor em Ciências Humanas - Sociologia e Política pela UFMG. Professor da Escola de Governo da Fundação João Pinheiro.

*** Mestre em Administração Pública pela Fundação João Pinheiro. Doutoranda em Sociologia pela Universidade de Coimbra.

${ }^{* * * *}$ Graduado em Ciências Econômicas pela UFMG. Graduando em Administração Pública pela Escola de Governo da Fundação João Pinheiro.
} 


\section{Introdução}

O trabalho aborda os movimentos sociais atuantes em Belo Horizonte na última década e que remetem à perspectiva do direito à cidade, tendo por objetivo analisar suas formas de organização e de ação coletiva sob o argumento de que se pode identificar uma pluralidade de repertórios de ação e de interação com o governo. ${ }^{1}$

No período analisado - de 2010 a $2017^{2}$-, a cidade foi palco de inúmeras ações coletivas, de natureza diversa, que incluem ações na linha do ativismo político ${ }^{3}$, mobilizadas a partir de temas nacionais no bojo dos ciclos de protestos que têm ocorrido no país. As manifestações de 2013, inicialmente, nuclearam-se em torno dos movimentos Passe Livre e dos Atingidos pela Copa e demarcaram um ciclo de protestos que tem sido objeto de abordagem (AVRITZER, 2016; ROMÃO, 2013; TATAGIBA, 2014). Mobilizaram atores organizados e mbém segmentos não organizados, com diversos motes e formas de ações coletivas. Nos momentos posteriores, ocorrem manifestações polarizadas que culminaram no impeachment da presidenta Dilma Rousseff e em uma crise institucional acompanhada de um novo ciclo de manifestações em protesto ao vigente governo.

Embora constituam um pano de fundo para a abordagem deste artigo, as ações coletivas e mobilizações políticas associadas às questões nacionais não serão contempladas. Focalizam-se os movimentos sociais recentes que retematizam a cidade com pautas associadas à perspectiva de reforma urbana e direito à cidade, referidas, nos termos de Harvey (2016), às possibilidades emancipatórias, de reinvenção da cidade. O que se tem em vista são os movimentos mobilizados desde uma perspectiva crítica e de questionamento da mercantilização do espaço urbano, de uma agenda de direito à cidade, de inclusão de

\footnotetext{
${ }^{1}$ No campo de estudos dos movimentos sociais, a noção de ação coletiva tem como uma das referências importantes: Mancur Olson, que problematiza as dificuldades de se empreender ações coletivas. A sociologia norte-americana dos movimentos sociais, especialmente a teoria de mobilização de recursos, privilegiou o emprego desta noção, mais ampla que a de movimentos sociais, considerando-se como chave a noção de repertórios de ação coletiva. Ver o cotejamento das noções de movimento social e de ação coletiva e ativismo em Millard e Takhard (2019).

2 O período analisado corresponde aos dois governos do Prefeito Márcio Lacerda (2009-2016) do Partido Socialista Brasileiro (PSB) e o primeiro ano do Prefeito Alexandre Kalil, atualmente filiado ao Partido Social Democrático (PSD).

3 Destaca-se a polissemia da noção de ativismo, que tem sido empregada em desenvolvimentos teóricos contemporâneos, seja no campo da teoria democrática, no qual tem-se contraposto ativismo e deliberação (FARIA, 2010), seja no campo dos movimentos sociais, apontando-se a discussão de Millard e Takhar (2019) em torno das noções de movimentos sociais, ação coletiva e ativismo. O ativismo tem-se definido a partir de caráter oposicional da ação coletiva, como em Young (2001), remetido ao confronto, obstrução, manifestações e protestos. De forma mais ampla Mansbridge (1990 apud FARIA, 2010, p. 109) remete o ativismo às formas de participação ampliada, para além das eleições, conectadas com movimentos sociais.
} 
democratização do planejamento e da gestão local.

Os movimentos sociais não constituem novidade em Belo Horizonte, que apresenta, desde os anos 1960, um tecido movimentalista significativo, incluindo os então chamados "movimentos sociais urbanos". Destaca-se também, como indicado por Avritzer e Pereira (2001), um tecido associativo expressivo e plural, com um grande número de associações civis temáticas e de demoradores.

No contexto de redemocratização, ao lado do fortalecimento de atores coletivos existentes, de reconfigurações e emergência de novos atores, tem-se uma diversidade de movimentos e mobilizações no campo das políticas sociais, de gênero e diversidade, dentre outros. Constitui um marco o governo da Frente BH-Popular, encabeçada por Patrus Ananias, do Partido dos Trabalhadores (PT), que se inicia em 1993 e tem continuidade programática nos governos até 2008. A partir de 1993 foi construída uma arquitetura participativa ampla e plural na cidade, envolvendo conselhos, orçamento participativo e conferências nos diversos setores de políticas e temas, ao lado de inovações nas políticas sociais e urbanas, endereçadas à inclusão e democratização. Os governos no período 20092016, do Prefeito Márcio Lacerda, não privilegiaram ou mesmo esvaziaram a dimensão participativa e, nesse contexto, distendeu-se o tecido movimentalista e pluralizaram-se as formas de ação coletiva. Ampliaram-se os movimentos com pautas endereçadas à democratização do espaço urbano, à inclusão social e das minorias, à preservação ambiental e do patrimônio.

O mapeamento desses movimentos sociais, realizado pelo artigo, agrupa-os em três modalidades principais, considerando as temáticas das características predominantes: movimentos de preservação do meio ambiente; de moradia, com destaque para as Brigadas Populares; e de direito à cidade, em que o Muitxs - Cidade que Queremos, é a principal referência, por sua pauta única e transversal. Além da diversidade temática, tais movimentos expressam diferentes perspectivas de relação com o governo. Na primeira modalidade, sua emergência é motivada por uma reação às iniciativas que se traduzem em ameaças de supressão à cobertura vegetal, advindas tanto do mercado imobiliário, quanto do próprio governo. Na segunda, eles se inscrevem na pauta do direto à moradia, da busca de alternativas à insuficiência do poder público em assegurar condições dignas de morar para os segmentos excluídos, recorrendo às ocupações. Já na terceira, os movimentos se estruturam a partir da perspectiva da inclusão e do aprofundamento democrático, movidos 
tanto pela insatisfação suscitada por decisões do governo local, no sentido de revertê-las, quanto pelo propósito de influenciar a agenda pública, no caso do Muitxs, com o lançamento de candidaturas à Câmara de Vereadores.

O mapeamento realizado, de natureza panorâmica, fundamenta-se na revisão da literatura pertinente à temática, de periódicos acadêmicos e de publicações da mídia, bem como de levantamentos de sítios da internet. A abordagem das formas de organização dos movimentos mapeados, os repertórios de ação coletiva e de interação com o governo, e como esses atores têm influído nas políticas locais apoia-se em levantamentos documentais, observação direta e, complementarmente, em entrevistas semiestruturadas com informantes-chave. ${ }^{4}$

O artigo está estruturado em quatro seções, além desta introdução e das considerações finais. A segunda seção discute o enquadramento teórico dos movimentos sociais, enfatizando suas formas de ação e interação com o sistema político-institucional. Nas seções seguintes abordam-se os movimentos sociais recentes em Belo Horizonte, que se associam de forma mais ampla à perspectiva de direito à cidade, buscando observar especialmente seus repertórios de ação.

\section{Movimentos Sociais, repertórios de ação e de interação}

O ambiente contemporâneo marca-se pelo alargamento das formas de participação social e ação coletiva, e pluralização dos movimentos sociais (WARREN, 2002). Em tal contexto, a categoria movimentos sociais mostra-se fluida e ambígua na literatura (ALONSO, 2009; DIANI; BISSON, 2010; GOHN, 2009).

Em esforço de síntese de elementos de correntes contemporâneas, Della Porta e Diani (1999) caracterizam os movimentos sociais como redes de interações informais entre uma pluralidade de indivíduos, grupos e/ou organizações engajadas em confronto político ou baseadas em elementos culturais e identidades coletivas compartilhadas. Ainda no sentido da caracterização dos movimentos sociais, Cohen e Arato (1992) apontam para sua natureza coletiva e caráter, primariamente, informal e extrainstitucional, para a expressão de conflitos sociais e as possibilidades de mudança que esses atores trazem em seu bojo.

\footnotetext{
${ }^{4}$ Para o artigo foram utilizadas entrevistas com um participante ativo das Brigadas; dois participantes do Muitxs, uma delas representante eleita.
} 
A literatura relativa aos movimentos sociais, de forma geral, apresenta uma perspectiva dicotômica, contrapondo institucionalização e contestação no que se refere às logicas e formas de ação de coletiva. Nesse sentido, o trabalho de Cohen constata a insuficiência das abordagens das duas linhagens da segunda metade do século $X X$, referenciando a tradição norte-americana moldada pela teoria de mobilização de recursos, e sua perspectiva de ação estratégica; e a tradição europeia, com sua ênfase cultural, sob o mote de novos movimentos sociais. Cohen e Arato (1992), em sua teoria da sociedade civil, avançam postulando lógicas e formas de ação coletiva complementares e não excludentes para os movimentos sociais contemporâneos, envolvendo tanto a construção de identidades coletivas quanto à orientação estratégica; e tanto as formas de ação contenciosas, quanto às formas de ação endereçadas a afetar o sistema político-institucional. No terreno dos novos movimentos sociais, já convergindo com a teoria democrática deliberativa, Melucci (1996, p. 191-192) sustenta que os movimentos sociais podem atuar de diferentes formas, destacando as possibilidades de afetarem os sistemas político-institucionais, no sentido de produzirem "algum tipo de reação que pode ser mais ou menos democrática", sem descartar as formas de participação mais institucionalizadas. Já no terreno subsequente à teoria da mobilização de recursos, a dimensão cultural comparece na produção de Tilly (1995, p. 26), na noção de repertório de ação coletiva, que (re)conceitua como "conjunto limitado de rotinas que são aprendidas, compartilhadas e postas em ação por meio de um processo relativamente deliberado de escolha." 5

Sob as rubricas de processo político e mobilização política, McAdam, McCarthy e Zald (1999) reformulam seus quadros teóricos. Destaca-se, nesse esforço, a concessão às dimensões ideacionais e cognitivas da ação, incorporando fundamentos culturais. A noção de frame ou enquadramento interpretativo constitui um núcleo da reconstrução. Para os autores, a emergência e o desenvolvimento dos movimentos associam-se à estrutura de oportunidades políticas, às formas de organização, e a processos coletivos de framing - de interpretação e de construção social.

Destacam-se ainda esforços de McAdam, Tarrow e Tilly (2009) em torno da chave

\footnotetext{
${ }^{5}$ A noção de repertório de Tilly (1978) refere-se a um conjunto limitado e historicamente enquadrado de performances alternativas que surgem, desaparecem, mudam e ou são inovadas. McAdam, Tarrow e Tilly (2009, p. 24) abordam os repertórios como expressão histórica da interação dos movimentos e opositores, apontando como grandes desempenhos a criação de associações e partidos, reuniões públicas, demonstrações, passeatas, petições pressão, ocupação de terras e imóveis, barricadas, ao lado de recursos associados à mídia e às tecnologias informacionais como a internet.
} 
"confronto político", na qual inscrevem movimentos sociais, ação coletiva e revolução. Em seus termos, essas formas de interação envolvem confronto ou reivindicações associadas aos outros interesses, sendo pelo menos um dos grupos na interação o governo. Os autores assinalam conexões entre movimentos sociais, identidades coletivas e redes sociais, indicando que a ação coletiva se vincula decisivamente às redes informais de interação; e que não há nenhuma descontinuidade fundamental entre os movimentos sociais e a política institucional. Entretanto, a despeito desses esforços, o tema das interações dos movimentos sociais com o Estado e o sistema político não mereceu atenção sistemática nas teorias dos movimentos sociais, não tendo sido contempladas a contento às formas de ação de cunho mais institucionalizado.

Nessa direção, Carlos (2015) problematiza a perspectiva de movimentos sociais como um fenômeno estritamente extrainstitucional, apontando para sua complexidade organizacional e interação com instituições e outros atores coletivos. A partir do contexto brasileiro, essa discussão tem comparecido, sob vários prismas, nos debates e desenvolvimentos teóricos e analíticos recentes no país (ABERS; BULLOW, 2011; CARLOS, 2015; TATAGIBA; PATERNIANI; TRINDADE, 2012), cabendo destacar a noção de repertórios de interação de Abers, Serafim e Tatagiba (2014), envolvendo as formas de interação entre movimentos sociais, atores coletivos e Estado.

No contexto brasileiro e latino-americano, nos quais, a partir dos processos de redemocratização, se desenvolveram formas de participação institucionalizada, os movimentos sociais têm atuado na construção de identidades e de bases para ação coletiva, e nas formas de mobilização, bem como nos espaços institucionalizados (DAGNINO, 2002). No Brasil, especialmente, destaca-se uma arquitetura participativa ampla e diversificada nos três níveis de governo, criada notadamente a partir da Constituição Federal de 1988 (CF-88), com um grande número de conselhos, conferências nacionais, orçamentos participativos, em tal contexto, os movimentos sociais e outros atores coletivos engajaram-se nas instituições participativas. Nesse sentido, cabe sublinhar a pluralidade das formas de ação coletiva, do ativismo e contestação às formas de participação institucionalizadas e dialógicas, que se revelam em um repertório plural de interação com o Estado.

A partir dessas experiências, os teóricos do processo político têm sido recentemente revistados por autores brasileiros. Algumas de suas noções-chave têm sido empregadas nas abordagens como a de oportunidade política, em Abers, Silva e Tatagiba 
(2018). Mais além, o conceito de repertório de ação tem sido reapropriado de forma a encampar a diversidade e complexidade das formas de ação coletiva no contexto brasileiro contemporâneo, ao exemplo dos trabalhos de Tatagiba, Paterniani e Trindade (2012), Lojekann (2013) e de Alonso (2017). Cabe ainda destacar a noção de repertórios de interação de Abers, Serafim e Tatagiba (2014), envolvendo a diversidade de formas de interação entre os movimentos sociais e atores coletivos societários com o Estado no contexto das políticas públicas.

\section{Movimentos de defesa do meio ambiente urbano}

Os movimentos em defesa do meio ambiente têm se multiplicado na cidade em defesa de áreas verdes remanescentes, como o "Salve a Mata do Planalto", o "Parque Jardim América", o "Fica Ficus" e o "S.O.S. Parque das Mangabeiras". O emprego das redes sociais, notadamente o facebook, configura-se como um meio de mobilização em todos os casos. 0 quadro 1 sintetiza esses movimentos, abordados em seguida.

Quadro 1 - Movimentos ambientalistas recentes em Belo Horizonte

\begin{tabular}{|c|c|c|c|}
\hline $\begin{array}{l}\text { Movimento e } \\
\text { ano de criação }\end{array}$ & $\begin{array}{l}\text { Significados } \\
\text { compartilhados e agenda }\end{array}$ & $\begin{array}{l}\text { Participantes e } \\
\text { Organização }\end{array}$ & $\begin{array}{l}\text { Repertórios de ação e de } \\
\text { interação com o governo } \\
\text { local }\end{array}$ \\
\hline $\begin{array}{l}\text { Salve a Mata } \\
\text { do Planalto } \\
(2020)\end{array}$ & $\begin{array}{l}\text { Luta contra a especulação } \\
\text { imobiliária e pela } \\
\text { preservação da } \\
\text { remanescente de mata } \\
\text { atlântica conhecida como } \\
\text { Mata do Planalto, e pelo } \\
\text { uso do local pela } \\
\text { população. }\end{array}$ & $\begin{array}{l}\text { Composto } \\
\text { principalmente } \\
\text { por moradores } \\
\text { dos bairros } \\
\text { Planalto, Campo } \\
\text { Alegre e Vila } \\
\text { Clóris, ao lado de } \\
\text { ambientalistas. }\end{array}$ & $\begin{array}{l}\text { O movimento se mobiliza } \\
\text { com carreatas, } \\
\text { caminhadas, atividades } \\
\text { culturais e apresenta } \\
\text { intenso uso das redes } \\
\text { sociais e da mídia local. } \\
\text { Institucionalmente, } \\
\text { participa em audiências } \\
\text { públicas e discussões com } \\
\text { o poder público. }\end{array}$ \\
\hline
\end{tabular}




\begin{tabular}{|l|l|l|l|}
\hline Parque Jardim & $\begin{array}{l}\text { Luta contra a especulação } \\
\text { imobiliária, pela } \\
\text { preservação da } \\
\text { remanescente de mata } \\
\text { atlântica e a criação de } \\
\text { um parque público na } \\
\text { área da antiga chácara } \\
\text { Jardim América. }\end{array}$ & $\begin{array}{l}\text { O movimento se } \\
\text { autodefine como } \\
\text { horizontal, aberto, } \\
\text { apartidário e sem } \\
\text { laços } \\
\text { institucionais, } \\
\text { composto por } \\
\text { moradores da } \\
\text { região oeste, } \\
\text { estudantes e } \\
\text { ambientalistas. }\end{array}$ & $\begin{array}{l}\text { O movimento se mobiliza } \\
\text { seustir de reuniões entre } \\
\text { passeatas e atividades } \\
\text { lúdicas, utilizando as } \\
\text { redes sociais para } \\
\text { divulgação e mobilização } \\
\text { para sua causa. Articula-se } \\
\text { com outros movimentos } \\
\text { ambientais da cidade e } \\
\text { participa de audiências } \\
\text { públicas. }\end{array}$ \\
\hline $\begin{array}{l}\text { Fica Ficus } \\
\text { (2020) }\end{array}$ & $\begin{array}{l}\text { Luta pela permanência } \\
\text { dos fícus da Avenida } \\
\text { Bernardo Monteiro, em } \\
\text { Belo Horizonte, bem como } \\
\text { pela manutenção dos } \\
\text { espaços verdes e } \\
\text { arborização das vias da } \\
\text { cidade. }\end{array}$ & $\begin{array}{l}\text { O movimento é } \\
\text { composto por } \\
\text { ambientalistas, } \\
\text { estudantes, } \\
\text { artistas e } \\
\text { moradores da } \\
\text { cidade, que } \\
\text { simpatizam-se } \\
\text { com a causa. }\end{array}$ & $\begin{array}{l}\text { O movimento atua a partir } \\
\text { de passeatas, atividades } \\
\text { lúdicas, e divulgação via } \\
\text { redes sociais. } \\
\text { Institucionalmente, } \\
\text { participa de audiências } \\
\text { públicas e reuniões com o } \\
\text { governo, tendo êxito com } \\
\text { a suspensão de cortes de } \\
\text { árvores. }\end{array}$ \\
\hline $\begin{array}{l}\text { S.O.S Parque } \\
\text { das } \\
\text { Mangabeiras }\end{array}$ & $\begin{array}{l}\text { Luta contra a privatização } \\
\text { do Parque das } \\
\text { Mangabeiras e pela } \\
\text { conservação ambiental da } \\
\text { fauna e flora do parque. }\end{array}$ & $\begin{array}{l}\text { Ambientalistas, } \\
\text { concessionários } \\
\text { que trabalham no } \\
\text { parque e } \\
\text { moradores dos } \\
\text { bairros vizinhos. }\end{array}$ & $\begin{array}{l}\text { O movimento atua a partir } \\
\text { de caminhadas, rodas de } \\
\text { conversas e eventos } \\
\text { conjuntos com outros } \\
\text { movimentos ambientais } \\
\text { locais. }\end{array}$ \\
\hline
\end{tabular}

Fonte: Pesquisa dos autores

O movimento Salve a Mata do Planalto (SMP) surgiu em 2009, a partir de uma reunião de moradores do Bairro Planalto motivada pelo fato de uma construtora ter obtido, junto à Prefeitura Municipal de Belo Horizonte (PMBH), autorização para a construção de um empreendimento imobiliário de porte em uma área urbana de 20 hectares - conhecida como Mata do Planalto -, remanescente de Mata Atlântica. Após a reação da comunidade, a construtora apresentou uma proposta na qual $70 \%$ da área seria preservada, com a criação de dois parques - um destinado aos moradores do empreendimento e outro público, a ser doado à $\mathrm{PMBH}$.

No entanto, o movimento SMP defende a preservação integral da área. Documentos elaborados pelo Ministério Público de Minas Gerais (MPMG) evidenciaram sua importância ambiental, servindo de base à emissão de duas recomendações contrárias ao

\footnotetext{
${ }^{6}$ Sobre o Fica Ficus, ver também Nascimento (2014).
} 
licenciamento.

Lutando contra a apropriação da mata pelo capital imobiliário, o SMP mobiliza-se em caminhadas, carreatas e atividades culturais, ao lado de formas de ação mais institucionalizada, como a participação em audiências públicas na Câmara Municipal relacionadas à temática. Destaca-se, ainda, sua articulação em rede com outros atores coletivos, da qual faz parte o Movimento de Associações de Moradores de BH (MAMBH), que integra mais de 40 associações e movimentos sociais.

O movimento Parque Jardim América (PJA) também se origina de reação a uma iniciativa do mercado imobiliário. Essa reação toma forma em 2011, quando moradores do bairro vizinho a uma área de cerca de 21 hectares, - Chácara do Jardim América - tiveram conhecimento de um processo em tramitação na $\mathrm{PMBH}$, solicitando licenciamento ambiental à implantação no local de um empreendimento residencial. Mobilizados, os moradores fizeram um abaixo-assinado e o encaminharam ao MPMG e à Secretaria Municipal de Meio Ambiente, obtendo uma liminar do MPMG suspendendo qualquer edificação até a decisão final do processo.

O PJA se define como um movimento horizontal, sem lideranças formais, aberto, apartidário e sem laços institucionais. O núcleo do movimento oscila entre vinte a trinta participantes, que se reúnem uma vez ao mês. As reuniões são marcadas via redes sociais, também utilizadas para divulgação das ações e objetivos do PJA. Apesar de perseguir um objetivo específico - a criação do parque -, o PJA mantém-se articulado com outros movimentos ambientais, integrando uma rede que objetiva a preservação dos espaços públicos e de áreas verdes. Mesmo transitando bem pelas instâncias institucionais, o movimento tem ressalvas à atuação do poder público que, em sua visão, tende a favorecer os interesses do capital.

O Fica Fícus surgiu em 2013, como reação ao corte e retirada dos exemplares de fícus ainda remanescentes da Av. Bernardo Monteiro, que constituíam um patrimônio ambiental e cultural da cidade. O movimento, que ganhou visibilidade a partir da mobilização nas redes sociais, volta-se para a preservação de espécies e áreas verdes na cidade, obtendo êxito em ações coletivas endereçadas ao cancelamento de derrubadas de árvores.

O Fica Fícus reivindica o direito à cidade, a participação na política e a manutenção de uma cidade sustentável com a preservação do "verde". Seu repertório de ações inclui a 
realização de mobilizações e ocupações lúdicas do espaço público, além da participação em audiências públicas e outras formas de ação institucionalizada. As mobilizações são realizadas e por meio de redes sociais (NASCIMENTO, 2014), e têm sensibilizado o governo.

O S.O.S. Parque Municipal das Mangabeiras se organizou em 2016, como protesto face ao Projeto de Lei $\mathrm{n}$ 1931, da PMBH, que abre a perspectiva de o referido parque ser administrado por meio de Parceria Público-Privada (PPP). Situado ao pé da Serra do Curral patrimônio ambiental e cultural eleita em 1997 como o símbolo da cidade - o parque, projetado por Burle Marx, tem uma área de 240 hectares, com vegetação remanescente típica do Cerrado e da Mata Atlântica. Concomitante ao valor ambiental, constitui-se em espaço de lazer para a população.

Além de defender a manutenção do parque como um espaço público, o movimento se preocupa com os impactos ambientais advindos da celebração da PPP. O projeto de lei afirma que a concessionária deverá preservar e resguardar as características naturais e patrimoniais do parque. Isto, no entanto, não é suficiente para evitar os questionamentos acerca dos impactos relacionados às intervenções estruturais que podem ocorrer no local em decorrência de projetos para geração de receita. A partir de caminhadas, debates, rodas de conversas e ações em conjunto com outros movimentos ambientais, o S.O.S. Parque das Mangabeiras busca a sensibilização do poder público para a manutenção do parque como bem público, defendendo o uso do espaço de forma gratuita e livre.

\section{Movimentos de moradia e as Brigadas Populares}

As lutas relativas ao direito à moradia não constituem novidade na cidade que, desde sua criação, tem ocupações informais, sendo palco da atuação de movimentos sociais urbanos, com um tecido de associações de bairro e de favelas expressivo, inclusive com federações e articulações desde meados do século anterior. Esse tecido se amplia e reconfigura na transição democrática, articulando-se em parte ao Movimento e Fórum Nacional de Reforma Urbana (FNRU), que logram influir na CF-88 e no Estatuto da Cidade.

Nesse campo, destaca-se a União Estadual por Moradia Popular (UEMP) ${ }^{7}$, que atua no estado e na cidade, vinculando-se ao FNRU. Na cidade, a UEMP atuou na produção

\footnotetext{
${ }^{7}$ A UEMP reúne movimentos por moradia em Minas Gerais e conecta-se à da UNMP (União Nacional por Moradia Popular) constituída em 1989. (UNIÃO NACIONAL POR MORADIA POPULAR, 2020).
} 
autogestionada de moradias no programa Crédito Solidário e tem representações em conselhos, além de promover a ocupação de um prédio na área central e participar de mobilizações, dentre outras formas de ação. Outro ator importante é o Movimento de Luta nos Bairros, Vilas e Favelas (MLB), que atualmente também se organiza no âmbito nacional e se articula ao FNRU. O MLB surgiu em 1999, inicialmente em Belo Horizonte (SILVA, 2012), e tem um papel relevante nas ocupações recentes ${ }^{8}$.

Importa destacar as novas ocupações urbanas, notadamente a partir de 2008, demarcando "novos territórios insurgentes" nos termos de Mayer (2015). Atualmente, existem em Belo Horizonte (RMBH) 16 novas ocupações urbanas, 12 das quais total ou parcialmente na capital, como indicado no quadro 2 . Tem-se um escopo de conflitos e situações fundiárias distintas, com algumas ocupações ameaçadas de remoção por via judicial, implicando formas diversas de mobilização dos atores coletivos envolvidos e apoiadores, a partir de manifestações nas ruas e nas redes sociais, ao lado de ações mais institucionalizadas.

Quadro 2 - Ocupações recentes em Belo Horizonte e Região Metropolitana

\begin{tabular}{|l|l|l|l|}
\hline Ocupações & Início & Localização & $\begin{array}{l}\text { No aprox. de } \\
\text { famílias }\end{array}$ \\
\hline $\begin{array}{l}\text { Camilo Torres (fração privada do } \\
\text { imóvel) }\end{array}$ & Fev./2008 & Barreiro/BH & 120 \\
\hline $\begin{array}{l}\text { Camilo Torres (fração pública do } \\
\text { imóvel) }\end{array}$ & Out/2008 & Barreiro/BH & 40 \\
\hline Dandara & Abr./2009 & Pampulha/BH & 1300 \\
\hline Irmã Dorothy & Mar./2010 & Barreiro/BH & 150 \\
\hline Zilah-Spósito/H. Greco & Nov./2011 & Venda Nova/BH & 250 \\
\hline Eliana Silva & Out./2012 & Barreiro/BH & 350 \\
\hline Guarani - Kaiowá & Mar./2012 & Ressaca-BH/Contagem & 150 \\
\hline Rosa Leão (Izidora) & Maio/2013 & Isidoro/BH & 2500 \\
\hline Esperança (Izidora) & Jun./2013 & Isidoro/BH & 1500 \\
\hline Vitória (Izidora) & Jul./2013 & Isidoro/BH & 4000 \\
\hline William Rosa & Out./2013 & Nacional BH/Contagem & 600 \\
\hline Nelson Mandela & Mar./2014 & Barreiro/BH & 310 \\
\hline Dom Tomas Balduíno & Jul./2014 & Betim & 110 \\
\hline Shekinah & Set./2014 & Betim & 100 \\
\hline Nova Canaã & Nov./2014 & Betim & 80 \\
\hline Paulo Freire & Maio/2015 & Barreiro/BH & 300 \\
\hline
\end{tabular}

\footnotetext{
${ }^{8}$ O MLB hoje se organiza no âmbito nacional, autodefinindo-se como "um movimento social nacional que luta pela reforma urbana e pelo direito humano de morar dignamente". Privilegia as ocupações em seu repertório de ação, entendendo que educam "o povo para a necessidade de lutar organizado e desenvolve o espírito de trabalho coletivo.". (MLB, 2020).
} 
Fonte: Mayer (2015, p. 233)

As Brigadas Populares (BPs), que têm papel proeminente nas ocupações, surgiram a partir de um grupo de estudos sobre marxismo de alunos da Faculdade de Direito da Universidade Federal de Minas Gerais (UFMG). Em 2006, parte desse grupo começou a realizar um trabalho social no Aglomerado da Serra, proporcionando um contato com uma associação local de moradores que se mobilizava para a ocupação de um prédio próximo. A partir daí, o grupo decidiu apoiar a iniciativa dos moradores - primeira ocupação na qual houve sua participação, conhecida como "Ocupação Caracol". Desde então, o movimento tem se destacado como importante ator nas lutas em prol da reforma urbana e nas ocupações na RMBH. (BRIGADAS POPULARES, 2020).

Contudo, a agenda política do movimento não se restringe à reforma urbana e direito à cidade. Sua atuação se dá em diversas outras temáticas, tais como o feminismo, as questões raciais e a luta antiprisional. O trabalho das BPs possui um forte componente territorial, que pode ser identificado pela formação de subgrupos chamados de Brigadas Territoriais, os quais atuam em alguma ocupação ou comunidade periférica.

De acordo com integrante das BPs, o coletivo não se define propriamente como um movimento social, por não ter uma pauta específica de mobilização, mas sim como uma organização política com objetivos mais amplos de disputa do poder político nacional, por meio da formação de uma força política de caráter militante e popular. Assim sendo, as BPs se propõem a idealizar e realizar um projeto político de país, o que aproxima seus objetivos aos de uma construção político-partidária, ainda que o grupo não se constitua legalmente como um partido político. Por outro lado, considerando suas características e repertório de ação, as BPs podem ser enquadradas como movimentos sociais por aspectos levantados pela literatura, tais como o caráter conflitual das ações coletivas, a presença de redes densas informais, a construção e o compartilhamento de valores, de ideais e de uma identidade coletiva.

Apesar de surgido na Faculdade de Direito da UFMG, o grupo que compõe atualmente as BPs é mais amplo e diverso, inclusive territorialmente. O movimento se expandiu inicialmente pelo estado e, em um segundo momento, articulou-se ao nível nacional com outros movimentos. Em 2011, houve um processo de fusão das BPs com outros três coletivos que possuíam uma linha de atuação similar e, desde então, o 
movimento se tornou nacional.

Em relação ao poder público, o próprio movimento classifica seu repertório de atuação em três orientações distintas: a resistência, contra o Estado; a linha reivindicativa, por meio do Estado; e a dimensão constituinte auto-organizativa, para além do Estado. Do ponto de vista da resistência, destaca-se a atuação na luta direta contra as ações de despejo das ocupações urbanas. Segundo integrante do movimento, as BPs conseguiram construir uma série de precedentes jurídicos no sentido de evitar as ações de despejos e assegurar formas mais dignas de tratar a remoção e o reassentamento das famílias moradoras de ocupações. Na linha reivindicativa, as BPs têm participado de mesas de negociação com o poder público, de conferências; atuado na Justiça por meio de ações populares; e reivindicado melhorias na prestação de serviços públicos para os moradores dos territórios onde atua. Na dimensão constituinte, atuam nas ocupações urbanas com uma perspectiva de construção de "comunas", orientada para a autogestão, a organização comunitária e a autonomia dos territórios.

Além disso, as BPs também têm se envolvido nas campanhas eleitorais, seja apoiando candidatos ligados às pautas defendidas pela organização ou lançando candidaturas próprias, como ocorreu recentemente na campanha do Muitxs.

\section{Movimentos de direito à cidade e o Muitxs}

Belo Horizonte tem sido cenário da emergência e atuação de diversos movimentos que podem ser agrupados em torno do mote do direito à cidade. Alguns desses movimentos são apresentados no quadro 3 , dos quais, se destaca, para fins de abordagem específica, o Muitxs.

Quadro 3 - Outros movimentos sociais que tematizam a cidade

\begin{tabular}{|c|c|c|c|}
\hline $\begin{array}{l}\text { Movimento } \\
\text { e Ano de Criação }\end{array}$ & $\begin{array}{l}\text { Significados } \\
\text { compartilhados e } \\
\text { agenda }\end{array}$ & $\begin{array}{l}\text { Participantes, } \\
\text { organização e atuação }\end{array}$ & $\begin{array}{l}\text { Repertórios de ação e } \\
\text { interação }\end{array}$ \\
\hline $\begin{array}{l}\text { Salve Santa } \\
\text { Tereza } \\
(2019,2020) \\
\text { Barros }(2016)\end{array}$ & $\begin{array}{l}\text { Luta contra a } \\
\text { especulação } \\
\text { imobiliária e } \\
\text { intervenções que } \\
\text { ameacem o bairro, } \\
\text { seu patrimônio e a }\end{array}$ & $\begin{array}{l}\text { Moradores do bairro, } \\
\text { mas aberto à } \\
\text { participação de } \\
\text { simpatizantes, e } \\
\text { articulado a outros } \\
\text { movimentos. }\end{array}$ & $\begin{array}{l}\text { Manifestações e encontros } \\
\text { na Praça Duque de Caxias; } \\
\text { pressão e diálogo com o } \\
\text { governo local. } \\
\text { No primeiro momento } \\
\text { logrou sucesso, conseguindo }\end{array}$ \\
\hline
\end{tabular}




\begin{tabular}{|c|c|c|c|}
\hline & $\begin{array}{l}\text { qualidade de vida da } \\
\text { população, } \\
\text { contraposto à } \\
\text { mercantilização da } \\
\text { cidade. }\end{array}$ & $\begin{array}{l}\text { Surgiu em } 1996 \text { diante da } \\
\text { mudança de legislação } \\
\text { urbanística e } \\
\text { especulação imobiliária, } \\
\text { ressurgindo em } 2013 \\
\text { diante de novas ameaças } \\
\text { de flexibilização da } \\
\text { legislação e de } \\
\text { destinação de uso do } \\
\text { Mercado público local. }\end{array}$ & $\begin{array}{l}\text { alterar a legislação de uso e } \\
\text { ocupação do solo, } \\
\text { preservando o patrimônio } \\
\text { desse bairro tradicional. A } \\
\text { partir de } 2013 \text { obteve outras } \\
\text { vitórias. }\end{array}$ \\
\hline $\begin{array}{l}\text { Praia da Estação } \\
\text { (2020) }\end{array}$ & $\begin{array}{l}\text { Luta contra a } \\
\text { privatização do } \\
\text { espaço público }\end{array}$ & $\begin{array}{l}\text { O movimento difuso e } \\
\text { abrangente emerge da } \\
\text { insatisfação quanto ao } \\
\text { Dec.3.863/2010, da } \\
\text { PMBH que limitava a } \\
\text { realização de eventos na } \\
\text { Praça da Estação. }\end{array}$ & $\begin{array}{l}\text { É realizada como } \\
\text { manifestação político- } \\
\text { cultural em diversas ocasiões } \\
\text { até o presente, na qual } \\
\text { manifestantes se encontram } \\
\text { na praça se apropriando dos } \\
\text { espaços. }\end{array}$ \\
\hline $\begin{array}{l}\text { Tarifa Zero BH } \\
\text { (2020) }\end{array}$ & $\begin{array}{l}\text { Lutas pela } \\
\text { democratização e } \\
\text { qualidade do } \\
\text { transporte público. } \\
\text { Propostas de } \\
\text { mudança na forma } \\
\text { de financiamento do } \\
\text { transporte público, a } \\
\text { partir do orçamento } \\
\text { público e não da } \\
\text { cobrança ao usuário. }\end{array}$ & $\begin{array}{l}\text { Originário de mobilização } \\
\text { das manifestações de } \\
\text { junho de } 2013 \text {, } \\
\text { autodefinido como um } \\
\text { movimento autônomo, } \\
\text { horizontal e } \\
\text { independente voltado } \\
\text { para a democratização } \\
\text { do transporte público na } \\
\text { cidade. }\end{array}$ & $\begin{array}{l}\text { Dentre as ações } \\
\text { extrainstitucionais, } \\
\text { destacam-se diversas } \\
\text { manifestações de rua, além } \\
\text { de um ônibus gratuito para } \\
\text { rodar na cidade. No campo } \\
\text { institucional, participa do } \\
\text { Conselho Municipal de } \\
\text { Mobilidade Urbana, do } \\
\text { Observatório de Mobilidade } \\
\text { Urbana, além de propor } \\
\text { ações orçamentárias nos } \\
\text { instrumentos de } \\
\text { planejamento do governo e } \\
\text { judiciais contra o aumento } \\
\text { tarifário em BH. }\end{array}$ \\
\hline $\begin{array}{l}\text { Viaduto Santa } \\
\text { Tereza Ocupado } \\
(2014)^{9}\end{array}$ & $\begin{array}{l}\text { Reivindica } \\
\text { transparência, } \\
\text { respeito e } \\
\text { participação popular } \\
\text { na obra de } \\
\text { revitalização do } \\
\text { Viaduto de Santa } \\
\text { Tereza, um dos } \\
\text { principais símbolos } \\
\text { arquitetônicos e } \\
\text { históricos da cidade. }\end{array}$ & $\begin{array}{l}\text { Em 08/02/2014 o } \\
\text { Viaduto foi ocupado em } \\
\text { protesto contra cerca } \\
\text { colocada pela PMBH, } \\
\text { envolvendo artistas, } \\
\text { praticantes de skate e } \\
\text { patins, dentre outros. A } \\
\text { partir dali passaram a } \\
\text { acontecer reuniões } \\
\text { periódicas em que a } \\
\text { comissão apresentava } \\
\text { demandas, quase todas } \\
\text { negadas e } \\
\text { desconsideradas. }\end{array}$ & $\begin{array}{l}\text { Ocupação do viaduto e } \\
\text { retirada das cercas de } \\
\text { isolamento, assembleias } \\
\text { periódicas entre os } \\
\text { integrantes do movimento e } \\
\text { reuniões com o poder } \\
\text { público para discussão do } \\
\text { projeto do viaduto. }\end{array}$ \\
\hline
\end{tabular}

\footnotetext{
${ }^{9}$ A ocupação cultural do viaduto tem ocorrido desde 2007, com o "Duelo de MCs" e movimento hip-hop e, adiante, em diversas ocasiões por diferentes atores e processos. Como antecedentes destaca-se ainda a Assembleia Popular Horizontal (APH), em 2013. (ASSEMBLEIA POPULAR HORIZONTAL: BELO HORIZONTE, 2020) voltada para discussão de diversos temas relativos à cidade (BERQUÓ,2016).
} 


\begin{tabular}{|c|c|c|c|}
\hline $\begin{array}{l}\text { Muitxs - Cidade } \\
\text { que Queremos } \\
\text { (MUITS..., 2016) } \\
\text { (GABINETONA, } \\
\text { 2020; MUITAS, } \\
\text { 2020; SOMOS } \\
\text { MUITAS, 2020) }\end{array}$ & $\begin{array}{l}\text { Luta pela } \\
\text { radicalização } \\
\text { democrática e do } \\
\text { direito à cidade, } \\
\text { além da inclusão de } \\
\text { minorias e do } \\
\text { combate às } \\
\text { opressões a partir da } \\
\text { ocupação } \\
\text { institucional do } \\
\text { legislativo municipal. }\end{array}$ & $\begin{array}{l}\text { O perfil dos participantes } \\
\text { é heterogêneo quanto a } \\
\text { faixa etária e profissão; } \\
\text { quanto à estratificação } \\
\text { por renda são } \\
\text { basicamente de classe } \\
\text { média ou média alta. O } \\
\text { movimento surge em } \\
\text { março de } 2015 \text { e passa a } \\
\text { reunir-se } \\
\text { Periodicamente com o } \\
\text { objetivo de pautar e } \\
\text { participar das eleições } \\
\text { municipais de } 2016 \text {. }\end{array}$ & $\begin{array}{l}\text { O movimento surge com o } \\
\text { objetivo específico de lançar } \\
\text { candidaturas nas eleições } \\
\text { municipais de 2016, } \\
\text { elegendo duas candidatas a } \\
\text { vereança. A mobilização se } \\
\text { deu nas reuniões periódicas } \\
\text { e divulgação das propostas } \\
\text { nas redes sociais. }\end{array}$ \\
\hline
\end{tabular}

Fonte: Pesquisa dos autores.

A identidade coletiva do "Muitxs" define-se a partir de três eixos principais de agenda política: o direito à cidade, a radicalização da democracia e a representatividade de minorias políticas. Seu surgimento está diretamente relacionado com o contexto político e cultural vivenciado em Belo Horizonte nos últimos anos, particularmente a partir de 2009, que pode ser considerado como oportunidade política. Tal contexto é marcado por uma efervescência de novos movimentos e manifestações que, de modo geral, se opõem a uma gestão pública municipal pouco aberta ao diálogo e à participação social e que adota um modelo de orientação neoliberal. Nessa conjuntura, diversas pautas passam a ser levantadas por diferentes grupos de atores da sociedade civil.

Primeiramente, a retomada do espaço público como local de festas e manifestações populares é pleiteada a partir de uma relação conflituosa do governo local com o movimento Praia da Estação, com o ressurgimento do carnaval de rua na cidade e com os eventos de hip hop. Paralelamente, as ocupações urbanas e a luta pelo direito à moradia são intensificadas por meio da atuação de movimentos como o MLB e as BPs. O processo de formação e organização desses novos atores coletivos é atravessado pelas manifestações de junho de 2013, que constituiu uma oportunidade política com muitos desdobramentos. Novos movimentos surgem na cidade a partir de então, com pautas diversas, associadas com aquilo que Lefebvre chamou, ainda na década de 1960, de "direito à cidade", retomado por Harvey (2016), que reconfiguram e dão novo fôlego a essa rede de ativistas.

Segundo integrante do Muitxs, o movimento se organiza a partir da afluência de algumas pessoas que participavam de ações de mobilização na cidade e que passam a se reunir periodicamente a partir de março de 2015, com o objetivo de pautar e participar das 
eleições municipais de 2016. Nos termos de outra integrante do Muitxs, o objetivo era de "ocupar a política", e sob esse mote organizou-se em 2016 o evento "Ocupa Política", com participantes de outros estados também mobilizados para a disputa eleitoral e construção de mandatos coletivos.

Uma de suas inspirações foram as plataformas municipalistas construídas na Espanha, como o "Ahora Madrid" e o "Barcelona en Comú", que conseguiram agregar diferentes movimentos sociais, ativistas e partidos, e elegeram, em 2015, candidatos às prefeituras em várias importantes cidades da Espanha, configurando o chamado “municipalismo cidadão" espanhol. ${ }^{10}$

Outra referência foi a memória de uma gestão popular vivenciada na cidade na década de 1990, já mencionada. Também contribuíram para moldar a identidade do Muitxs os repertórios de ação e performances dos movimentos sociais recentes na cidade e o próprio diálogo com esses atores coletivos. Embora a disputa eleitoral tenha sido o objetivo, o movimento se propôs a experimentar novas formas de exercer a democracia, com inversão da lógica elitista da representação. Idealizou-se assim, uma nova forma de representação, com mandatos abertos, coletivos e participativos, postos adiante em prática a partir das vitórias eleitorais. ${ }^{11}$ Portanto, a radicalização democrática é outro eixo estruturante do coletivo.

Um terceiro eixo fundamental na organização do Muitxs trata da inclusão de minorias e do combate às opressões. Esse eixo engloba as questões indígena, das mulheres, das pessoas negras, das pessoas trans, dos homossexuais, das juventudes e também dos animais.

Inicialmente, o movimento organizou-se a partir de reuniões abertas e promoveu diversos encontros temáticos. Tais encontros foram realizados em diferentes locais da

\footnotetext{
${ }^{10}$ A experiência do municipalismo cidadão molda-se a partir do movimento 15M na Espanha, em 2011. Da efervescência movimentalista no período constroem-se frentes de cidadãos e candidaturas aos governos locais, bem sucedidas em nove capitais e dezenas de cidades nas eleições de 2015, com destaque para Barcelona, com Ada Colau, e Madri, com Manoela Carmona. A agenda dessas frentes ancora-se na perspectiva de participação nas decisões e de aprofundamento democrático, bem como de uma agenda urbana endereçada ao direto à cidade, à economia cidadã, à ecologia urbana e bem estar de proximidade, como construções comuns. Sobre as experiências do municipalismo cidadão espanhol, ver Blanco, Carmona e Subirats (2018).

${ }^{11}$ Ver o site da Gabinetona "que se define como "uma experiência de ocupação cidadã da política" [...] sem precedentes na política brasileira". A Gabinetona reúne 4 mandatos parlamentares e 90 ativistas e trabalhadores envolvidos. Nessa linha, uma trilha importante de abordagem do Muitxs e da Gabinetona é a partir das discussões sobre representação, na medida em que por meio dos mandatos coletivos, organicamente construídos, tem-se uma inovação democrática nada trivial (GABINETONA, 2020).
} 
cidade, abarcando os temas da moradia, mobilidade urbana, áreas verdes, democracia, cultura e feminismo. Concomitantemente, o grupo desenvolveu uma plataforma colaborativa virtual similar às plataformas que foram utilizadas nas campanhas eleitorais da Espanha. O objetivo era construir um programa de campanha colaborativo, a partir das contribuições de qualquer cidadão que se cadastrasse no site da plataforma.

No entanto, para entender a trajetória do "Muitxs" é importante ressaltar uma diferença entre os sistemas eleitorais brasileiro e espanhol. No caso espanhol, os eleitos não possuíam vínculo com os partidos tradicionais, sendo alguns deles candidatos independentes. No caso brasileiro, o sistema eleitoral não permite candidaturas sem partido. Portanto, uma das frentes de atuação do movimento foi a articulação e a conversa com os partidos existentes, com uma aposta ambiciosa de realizar um "transbordamento dos partidos", isto é, fazer com que a movimentação ganhasse força, de tal modo que os partidos iriam apenas compor uma frente de atores mais ampla, como ocorreu na Espanha.

Na prática, o Muitxs conversou com diversas organizações e partidos políticos; ao final, optou-se coletivamente pela filiação no Partido Socialista e Liberdade (PSOL). A justificativa deveu-se tanto à convergência das pautas defendidas quanto à importância pragmática de se concentrar as possíveis candidaturas em uma única legenda, para atingir o quociente eleitoral.

Nas eleições municipais de 2016, foram lançadas 12 candidaturas à vereança em uma campanha coletiva com o slogan: "Votou em uma, votou em todas". A campanha foi realizada de maneira integrada e coordenada por meio da criação de um atelier criativo, onde diversas pessoas se inscreveram para trabalhar voluntariamente. Durante a campanha, outras pautas foram incorporadas à identidade do grupo, como a legalização da maconha e a luta antiprisional. Em um manifesto lançado em sua página do facebook, um dos princípios do movimento era lançar "candidaturas que levem ao protagonismo os sujeitos das lutas sociais, corpos que expressem a diversidade de gênero, raça, orientação sexual e territórios, buscando-se a paridade" (MUITXS..., 2016). Do ponto de vista representativo, 8 das 12 candidaturas eram mulheres e havia a presença de candidatas negras, além de uma mulher trans e de uma mulher indígena. Outra marca da campanha foi o questionamento dos privilégios parlamentares e, nesse sentido, todas as candidatas assumiram um compromisso firmado em cartório de doar parte de seus salários e abrir mão de algumas das verbas parlamentares, caso eleitas. Dos 46 mil votos obtidos pela coligação PSOL-PCB, mais de 35 
mil foram destinados às candidaturas do Muitxs - votação suficiente para eleger 2 candidatas, sendo uma delas a mais votada do município. Nas recentes eleições para o legislativo, ocorridos em 2018, o movimento reitera a estratégia de disputar vagas por meio de campanha coletiva. Houve o lançamento de 12 candidaturas, envolvendo candidaturas para a Assembleia Legislativa de Minas Gerais, a Câmara e o Senado Federal. Destas lançadas 2 candidatas foram eleitas, uma para a Assembleia Legislativa e outra para a Câmara.

\section{Considerações finais}

O mapeamento apresentado permite perceber a multiplicidade, a complexidade e a diversidade de movimentos atuantes na linha do direito à cidade que se organizam em Belo Horizonte na última década. A extensão e mesmo ampliação recente desse tecido movimentalista pode ser associada, a partir de 2013, em parte ao contexto nacional, marcado por um ciclo de mobilizações, que se constituí como oportunidade política. No entanto, o percurso incita às indagações, podendo-se atribuir o florescimento de novos atores e formas de ação coletiva ao contexto do governo local, seja pela orientação neoliberal no tratamento da questão urbana, seja pelo relativo esvaziamento das instituições participativas e práticas de participação institucionalizada.

Em relação às pautas e significados construídos pelos movimentos, que constituem lastros para a ação coletiva, a despeito de sua pluralidade, pode-se apontar para a perspectiva de direito à cidade, de democratização da cidade e de sua gestão, para as possibilidades de inclusão, bem como para as conjunções de propostas de cunho reformista e mesmo revolucionário. Para além das diferentes pautas e bases sociais e organizativas, pode-se observar um repertório de ação plural, que inclui desde protestos e ocupações a outras formas de manifestação por meio de atividades como eventos culturais, feiras, exposições, caminhadas e rodas de conversas, notando-se uma tendência de ocupação do espaço público. Em paralelo, formas de participação institucionalizada também estão presentes e se desdobram em um repertório de interação diverso com o governo local: participação em audiências públicas; tentativas de diálogo com representantes do poder público em torno dos conflitos urbanos específicos ou referentes ao plano diretor e à legislação urbano-ambiental; e participação em instituições participativas, como conselhos e conferências. Destaca-se ainda que, em todos os casos, a internet e as redes sociais têm sido 
fartamente empregadas e desempenham um papel relevante nos intercâmbios de informações, na articulação dos movimentos entre si, seja no âmbito local ou de forma mais ampla, no âmbito nacional, e, especialmente nas mobilizações, alargando os repertórios de ação e ampliando apoios.

Buscou-se explorar, no artigo, a diversidade de formas de ação coletiva dos movimentos, que ultrapassam clivagens simplistas. As BPs, em sua relativa radicalidade, mostram-se emblemáticas nesse sentido, ao assumirem repertórios de ação em uma tríade: resistir/lutar/ocupar numa orientação contra o Estado; reivindicar, em uma orientação dialógica ou participativa; e a auto-organização, construção de bases e práticas. Já o Muitxs expressa uma quarta via de ação coletiva, direcionada a "ocupar a política", especificamente o espaço institucional legislativo.

A despeito dessa diversidade, os movimentos analisados sustentam, sem exceção, uma dupla trilha de ação, do ativismo e contestação aos diálogos com o governo local e à participação institucionalizada. Em distintas medidas, esses atores coletivos têm atuado por meio de mobilizações e manifestações, de ocupações que concretizam o direito à cidade e à moradia digna, bem como, em alguns casos, de formas de ação que recriam o espaço urbano como locus do encontro e da festa na linha Lefebvriana.

\section{Referências}

ABERS, Rebecca; BULOW, Marisa Uon. Movimentos sociais na teoria e na prática: como estudar o ativismo através da fronteira entre estado e sociedade? Sociologias, Porto Alegre, v. 13, n. 28, p. 52-84, 2011.

ABERS, Rebecca; SERAFIM, Lizandra; TATAGIBA, Luciana. Repertórios de interação estadosociedade em um estado heterogêneo: a experiência na era Lula. Revista de Ciências Sociais, Rio de Janeiro, v. 57, n. 2, p. 325-357, 2014.

ABERS, Rebecca; SILVA, Marcelo Kunrath; TATAGIBA, Luciana. Movimentos sociais e políticas públicas: repen- sando atores e oportunidades políticas. Lua Nova, São Paulo, v. 105, p. 1548, 2018.

ALONSO, Angela. A política das ruas: protestos em São Paulo de Dilma e Temer. Julho. Novos Estudos Cebrap, São Paulo, n. esp., p. 49-58, 2017.

ALONSO, Angela. As teorias dos movimentos sociais: um balanço do debate. Lua Nova, São Paulo, v. 76, p. 49-86, 2009.

ASSEMBLEIA POPULAR HORIZONTAL: BELO HORIZONTE. Belo Horizonte, 2020. Facebook: AssembleiaPopularBH. Disponível em: https://www.facebook.com/AssembleiaPopularBH/. 
Acesso em: 20 maio 2020.

AVRITZER, Leonardo. Impasses da democracia no Brasil. Rio de Janeiro: Civilização Brasileira, 2016.

AVRITZER, Leonardo; PEREIRA, Maria de Lourdes Dolabela. Democracia, participação e instituições híbridas. Teoria e Sociedade, Belo Horizonte, n. esp., 2001.

BARROS, Pedro Caldeira. Movimentos sociais e políticas públicas: um estudo de caso do movimento salve Santa Tereza. 2016. Dissertação (Mestrado em Administração Pública) Escola de Governo Professor Paulo Neves de Carvalho, Fundação João Pinheiro, Belo Horizonte, 2016.

BERQUÓ, P.B. A ocupação e a produção de espaços biopotentes em Belo Horizonte: entre rastros e emergências. Dissertação (mestrado) - Universidade Federal de Minas Gerais, Escola de Arquitetura,2016.

BLANCO, Ismael; CARMONA, Ricard Gomà; SUBIRATS, Joan. El nuevo municipalismo: derecho a la ciudad y comunes urbanos. Gestión y Análisis de Políticas Públicas, Madrid, n. 20, p. 1428, 2018.

BRIGADAS POPULARES. Disponível em: https://brigadaspopulares.org.br/. Acesso em: 20 maio 2020.

CARLOS, Euzenéia. Movimentos sociais e sistema político nas teorias dos movimentos sociais. Intercepções, Rio de Janeiro, v. 17, n. 1, p. 15-53, 2015.

COHEN, Jean; ARATO, Andrew. Civil society and political theory. Cambridge: Mit Press, 1992.

DAGNINO, Evelina. Sociedade civil, espaços públicos e construção democrática no Brasil: limites e possibilidades. In: DAGNINO, Evelina (org.). Sociedade civil e espaços públicos no Brasil. São Paulo: Paz e Terra, 2002. p. 279-303.

DELLA PORTA, Donatella; DIANNI, Mario. Social movements: an introduction. 2. ed. Oxford: Blackwell, 1999.

DIANI, Mario; BISON, Ivan. Organizações, coalizões e movimentos. Revista Brasileira de Ciência Política, Brasília, n. 3, p. 220-249, 2010.

FARIA, Cláudia Feres. O que há de radical na teoria democrática contemporânea: análise do debate entre ativistas e deliberativos. Revista Brasileira Ciências Sociais, v. 25, n. 73, p. 101111, 2010.

FICA FICUS. Belo Horizonte, 2020. Facebook: ficaficus. Disponível em: https://www.facebook.com/ficaficus. Acesso em: 20 maio 2020.

GABINETONA. Ocupar a política com cidadania e ousadia. Disponível em: https://gabinetona.org/site/. Acesso em: 20 maio 2020.

GOHN, Maria da Glória. Novas teorias dos movimentos sociais. 2. ed. São Paulo: Loyola, 
2009.

HARVEY, David. Cidades rebeldes. Rio de Janeiro: Martins Fontes, 2016.

LOJEKANN, Cristiana. Mobilização do direito como repertório de ação coletiva e crítica institucional no campo ambiental brasileiro. Dados, Rio de Janeiro, v. 56, n. 2, p. 311-349, 2013.

MAYER, Joviano Gabriel Maia. O comum no horizonte da metrópole biopolítica. 2015. Dissertação (Mestrado em Arquitetura e Urbanismo) - Universidade Federal de Minas Gerais, Belo Horizonte, 2015.

MLB - MOVIMENTO DE LUTA, NOS BAIRROS, VILAS E FAVELAS. Disponível em: https://www.mlbbrasil.org/. Disponível em: 20 maio 2020.

McADAM, Doug; TARROW, Sidney; TILLY, Charles. Para mapear o confronto político. Lua Nova, São Paulo, n. 76, p. 11-48, 2009.

McADAM, Dough; McCARTHY, John D.; ZALD, Mayer N. Comparative perspectives on social movements: political opportunities, mobilizing structures, and cultural framings. Cambridge: Cambridge University, 1999.

MELUCCl, Alberto. Challenging codes: collective action in the information age. Cambridge: University press, 1996.

MILLARD, P.; TAKHAR, S. Social movements, collective action and activism. Sociology, Oxford, v. 53, n. 3, p. 1-12, 2019.

MUITAS. Belo Horizonte, 2020. Facebook: asmuitas. Disponível em: https://www.facebook.com/asmuitas. Acesso em: 20 maio 2020.

MUITXS, a cidade que queremos. Ocupar as eleições com cidadania e ou sadia. 2016. Disponível em: http://www.muitxs.org/manifesta/. Acesso em: 7 abr. 2017.

NASCIMENTO, José N. A cidade é um negócio? movimentos sociais e o espaço público: o caso do Fica Fícus em BH. In: COLÓQUIO IBERO-AMERICANO PAISAGEM CULTURAL, PATRIMÔNIO E PROJETO, 3., 2014, Belo Horizonte. Anais [...]. Belo Horizonte, 2014. Disponível em: http://www.forumpatrimonio. com.br/paisagem2014/trabalho/116/a-cidade-e-um-negociomovimentos-sociais-e-o-espaco-publico-o-caso-do-fica-ficus-em-bh. Acesso em: 21 abr. 2017.

PARQUE JARDIM AMÉRICA. Belo Horizonte, 2020. Facebook: ParqueJAbh. Disponível em: https://www.facebook.com/pg/ParqueJAbh/about/?ref=page_internal. Acesso em: 20 maio 2020.

PRAIA DA ESTAÇÃO. Belo Horizonte, 2020. Facebook: praiadaestação. Disponível em: https://pt-br.facebook.com/praiada.estacao. Acesso em: 20 maio 2020.

ROMÃO, Wagner de Melo. As manifestações de junho e os desafios à participação institucional. In: INSTITUTO DE PESQUISA ECONÔMICA APLICADA - IPEA. Boletim de análise 
político-institucional. Rio de Janeiro: IPEA, 2013. p. 11-17.

SALVE A MATA DO PLANALTO. Belo Horizonte, 2020. Facebook: salveamatadoplanalto. Disponível em:

https://www.facebook.com/pg/salveamatadoplanalto/about/?ref=page_internal. Acesso em: 20 maio 2020.

SALVE SANTA TEREZA. Belo Horizonte, 2020. Facebook: movimentosalvesantatereza. Disponível em: https://www.facebook.com/movimentosalvesantatereza/. Acesso em: 20 maio2020.

SANTA TEREZA TEM. Comunidade: Associação Comunitária do bairro Santa Tereza e Movimento Santa Tereza. 2019. Disponível em: https://santaterezatem.com.br /2019/05/15/comunicado-da-associacao-comunitaria-do-bairro-santa-tereza-e-movimentosalve-santa-tereza/. Acesso em: 20 maio 2020.

S.O.S. PARQUE DAS MANGABEIRAS. Belo Horizonte, 2020. Facebook: s.o.s.mangabeiras. Disponível em: https://www.facebook.com/s.o.s.mangabeiras. Acesso em: 20 maio 2020.

SILVA, Cleiton Ferreira. O movimento de luta nos bairros, vilas e favelas (MLB) e a política de autogestão: análise de uma experiência no bairro Iputinga. 2012. Dissertação (Mestrado em Geografia) - Universidade Federal da Paraíba, Recife, 2012.

SOMOS MUITAS. Somos muitas e juntas seremos mais. Disponível em: https://www.somosmuitas.com.br/. Acesso em: 20 maio 2020.

TARIFA ZERO BH. Belo Horizonte, 2020. Facebook: tareifazerobh. Disponível em: https://www.facebook.com/tarifazerobh/. Acesso em: 20 maio 2020.

TATAGIBA, Luciana. Sobre ciclos de protestos e democracia no Brasil. Revista Política \& Sociedade, Florianópolis, v. 13, n. 28, 2014.

TATAGIBA, Luciana; PATERNIANI, Stella Zagatto; TRINDADE, Thiago Aparecido. Ocupar, reivindicar, participar: sobre o repertório de ação do movimento de moradia de São Paulo. Opinião Pública, Campinas, v. 18, n. 2, p. 399-426, 2012.

TILLY, Charles. Contentious repertoires in Great Britain. In: MARK, Traugott (ed.). Repertoires and cycles of collective action. Durham: Duke University Press, 1995.

TILLY, Charles. From mobilization to revolution. Nova York: Random House, 1978.

UNIÃO NACIONAL POR MORADIA POPULAR. O que é a UNMP. Disponível em: http://www.unmp.org.br/2008/05/27/uemp-mg/. Acesso em: 20 maio 2020.

WARREN, Mark E. What does participation means today? Political Theory, Beverly Hills, v. 30, n. 5, p. 677-701, 2002.

YOUNG, Iris Marion. Activist challenges to deliberative democracy. Political Theory, Beverly Hills, v. 29, n. 5, p. 670-690, 2001. 
Recebido em: 14.10.2019

Aceito em: 01.04.2020 